\title{
COCONUT BISEXUAL FLOWERS AND THEIR SIGNIFICANCE FOR HYBRID SEED GARDENS
}

\author{
T.A. Davis and R.B. Maliangkay ${ }^{1}$
}

\begin{abstract}
Among the tall and dwarf varieties of coconut as well as the hybrids between them, occasionally one comes across hermaphrodite or bisexual flowers. Some indNridual palms produce a high percentage of hermaphrodite flowers while a great majority of others do not produce any bisexual flower at all. There is clear evidence that coconut flowers at the primordial stage are bisexual with the potential. to develop both stamens and pistils in the same flower. But at a later stage of development, one grows into a female flower whose male organs are reduced to a ring of six staminodes. Another develops into a staminate flower whose pistils are reduced to three pistillodes. However, due to genetic, ecological, physiological or other factors, some unisexual. flowers show an atavistic display of hermaphroditisin. Bisexual flowers are observed among tall. and dwarf variety palms. The negligible percentage of bisexual flowers that occur in large estates where the fruits are not used as seeds has no major disadvantage. But in seed gardens, especially where inter-varietal hybrid seeds are produced, hermaphrodite flowers are capable of reducing the percentage of true hybrids. Timely removal of hermaphrodite flowers, therefore, would reduce the occurrence of undesirable true-to-mother type progeny and enhance the success of intervarietal hybridization,
\end{abstract}

\section{Hermaphrodite flowers among coconut varieties}

Of the early investigators who studied the differentiation, development and morphology of coconut flowers are Petch (1913), Juliano and Quisumbing (1931) and Patel. (1938). Eventhough coconut flower has the potential to develop into a hermaphrodite flower as is the case with some other palms (Corypha, Copemicia, Korthalsia, Licuala, Dyistona, Prichardia, Thrinax and Washingtonia), coconut palm produces only unisexual, flowers, both the males and females being: distributed on the same spadix. Rao (1948) for the first time reported an exceptional case of bisexual flower in coconut. Davis et al (1954) located four palms within the farm of the Coconut Research Station, Kayangulam in Kerala State (India) that produced large numbers of herinaphrodite flowers, in additioft to the usual numbers, of male and female flowers. These fourpolygamo-monoecious palms produced one or more hermaphrodite flowers in every spadix we could examine. Figure 1 shows portion of five spikes bearing male, female and hermaphrodite flowers drawn from one of these palms. Numbers of normal female flowers and bisexual flowers recorded in some spadices are presented in Table 1.

Tree No. VI/311 produced the highest (36.83 percent) hermaphrodite flowers when the total of female and hermaphrodite flowers are considered togetner. One inflorescence even produced more hermaphrodite flowers than pure females. The other trees produced $26.11 \%, 14.83 \%$ and $9.89 \%$ bisexual flowers respectively. Thus, about $25.55 \%$ of the flowers produced in the spadices examined of the four palms were hermaphrodite flowers. It is likely that these four palms could be the progeny of a parent which had a genetic potential for bisexual flowers.

\footnotetext{
${ }^{1}$ J.B.S. Haldane Research Centre, Nagercoil 4, Tamilnadu, India and Coconut Research Institute, Manado, Indonesia, respectively.
} 


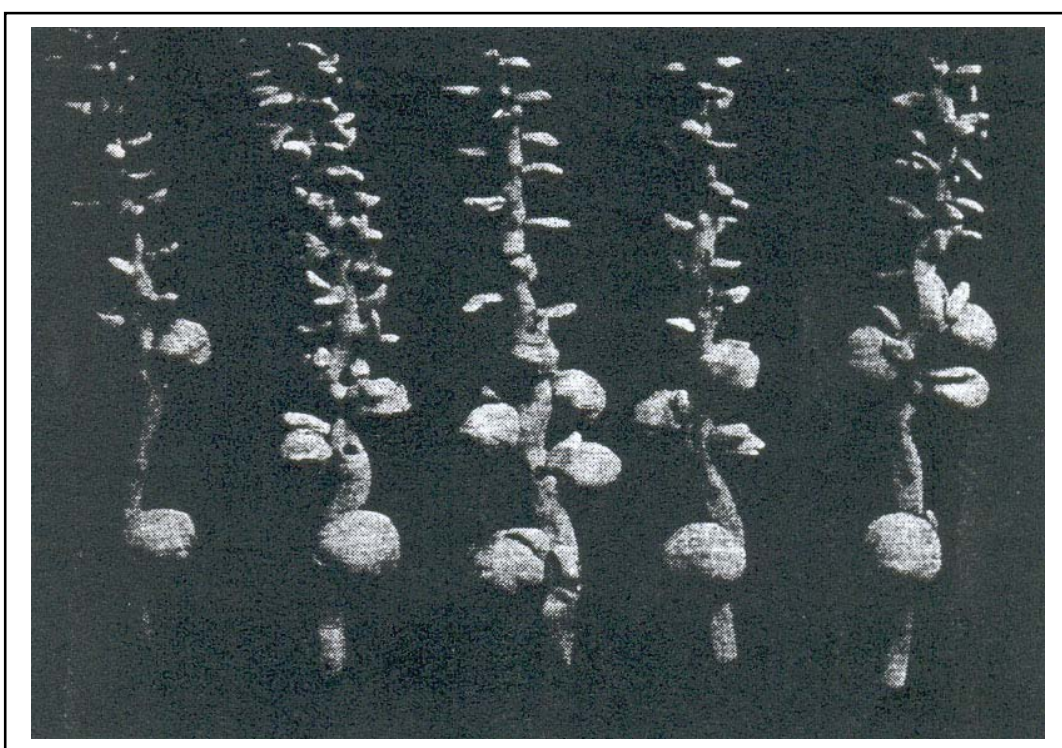

Figure 1. Basal portion of 5 coconut spikes of West Coast of India Tall variety bering female, hermaphrodite and male flowers.

Table 1.

Distribution of female and hemaphrodite flowers in $\mathbf{4}$ coconut palms

\begin{tabular}{|c|c|c|c|c|c|c|c|c|c|c|}
\hline \multicolumn{3}{|c|}{ Tree No. VI/311 } & \multicolumn{2}{|c|}{ Tree No. I/179 } & \multicolumn{2}{|c|}{ Tree No.IV/227 } & \multicolumn{2}{|c|}{ Tree No. III/338 } & \multicolumn{2}{|c|}{ Total } \\
\hline Spadix & O flrs & $\widehat{o f l r s}$ & ○ flrs & $\widehat{o f l r s}$ & Oflrs & $\widehat{f l r s}$ & o flrs & $\widehat{o}$ flrs & o flrs & $\lesssim$ flrs \\
\hline 1. & 63 & 70 & & & & & & & 63 & 70 \\
\hline 2. & 54 & 39 & & & & & & & 54 & 39 \\
\hline 3. & 32 & 21 & 41 & 7 & & & & & 73 & 28 \\
\hline 4. & 34 & 17 & 16 & 4 & & & & & 50 & 21 \\
\hline 5. & 20 & 11 & 29 & 11 & & & & & 49 & 22 \\
\hline 6. & 21 & 7 & 39 & 9 & & & & & 60 & 16 \\
\hline 7. & 20 & 11 & 40 & 8 & & & & & 60 & 19 \\
\hline 8. & 30 & 7 & 16 & 11 & & & & & 46 & 18 \\
\hline 9. & 20 & 11 & 16 & 7 & & & & & 36 & 18 \\
\hline 10. & 40 & 21 & 16 & 8 & & & & & 56 & 29 \\
\hline 11. & 21 & 12 & 14 & 8 & & & & & 35 & 20 \\
\hline 12. & - & - & 12 & 7 & & & & & 12 & 7 \\
\hline 13. & 41 & 16 & 13 & 4 & & & & & 54 & 20 \\
\hline 14. & 39 & 16 & 11 & 4 & 81 & 11 & & & 131 & 31 \\
\hline 15. & 53 & 37 & 15 & 7 & 69 & 16 & 89 & 7 & 226 & 67 \\
\hline 16. & 46 & 31 & 11 & 4 & 101 & 17 & 81 & 10 & 239 & 62 \\
\hline 17. & 73 & 36 & 14 & 4 & 64 & 4 & 46 & 7 & 197 & 51 \\
\hline 18. & 61 & 27 & 16 & 6 & 48 & 12 & 46 & 6 & 171 & 51 \\
\hline 19. & - & - & 15 & 9 & 85 & 18 & 97 & 5 & 197 & 32 \\
\hline Total & 668 & 390 & 334 & 118 & 448 & 78 & 359 & 35 & 1,909 & 621 \\
\hline
\end{tabular}


The four palms mentioned above belong to the tall variety coconut (West Coast of India Tall). Davis came across another tall variety palm in West Coast of India which showed a greater variation in its spadix. The spikes in Fig. 2 show a clear transition in the expression of sex among the different kinds of flowers. At the base of practically every spike, there are two female flowers that remam pressed together and appear as twins. Such twin female flowers occur frequently in the spadix of variety spicata recorded by Jacob (1941). Farther from the female flowers, the spike is free from any flower for a length of $2-3 \mathrm{~cm}$. The hermaphrodite flowers appear next. Here, each spike bears 2-7, spherical flowers that resemble females although their size is smaller than normal female flowers. These are the hemaphrodite flowers which produce both functional pistils and stamens. Some of them even develop into fruits. Beyond the region of bisexual flowers the numerous male flowers are distributed. Among the male flowers too, the size and potentiality gradually get diminished towards the tip of spikes where the flowers are the smallest and sterile. The male flowers placed, close to the bisexual flowers are fully developed and bear six functional stamens each. Thus, this particular tall variety palm is remarkable in its expression of sex

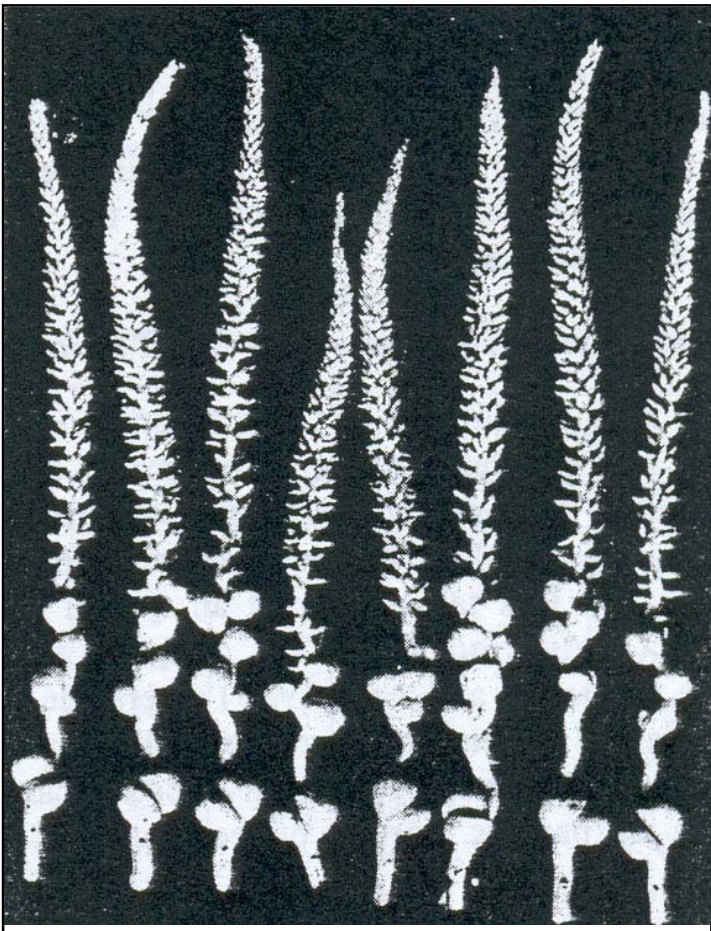

Figure 2. Coconut spikes from a tall variery, polygamo-monoecious spadix. In each spike, the lowest are twin female flowers followed by 3-7 hermaphrodite flowers. The males occupy the distal portion of spikes. within the same spadix. Unfortunately, even before collecting seeds for preservetion and study of such a genetic variation, the tree was felled to give room for a highway.

\section{Hermaphrodite flowers in Nias yellow dwarf coconut}

For the mass production of D x T hybrid coconuts in Indonesia for the national rejuvenation programme, the Cocconut Research Institute, Manado employed only one dwarf seed parent which is the indigenous Nias yellow dwarf and three pollen parents (Tenga, Palu and Bali talls) covering an area of about 600 ha of seet gardens (Davis et al, 1985). The design of the seed garden is a novel one (Liyanage and Aziz, 1983) where the seed parents (4 rows) are planted alternating a row of pollen parents within the same, garden whic is bordered by an effective barrier of 8 guard raws of the tall parents. Portion of seed garden is seen in Fig. 3. We made a survey for the presence of bisexual flowers in some dwarf palms of the Paniki seed garden in North Sulawesi Province. One dwarf palm in this garden was found to produce a few bisexual flowers. One of its spadices bearing 32 spikes and producing a number of bisexual flowers was examined in detail. and the data are presented in Table 2. 


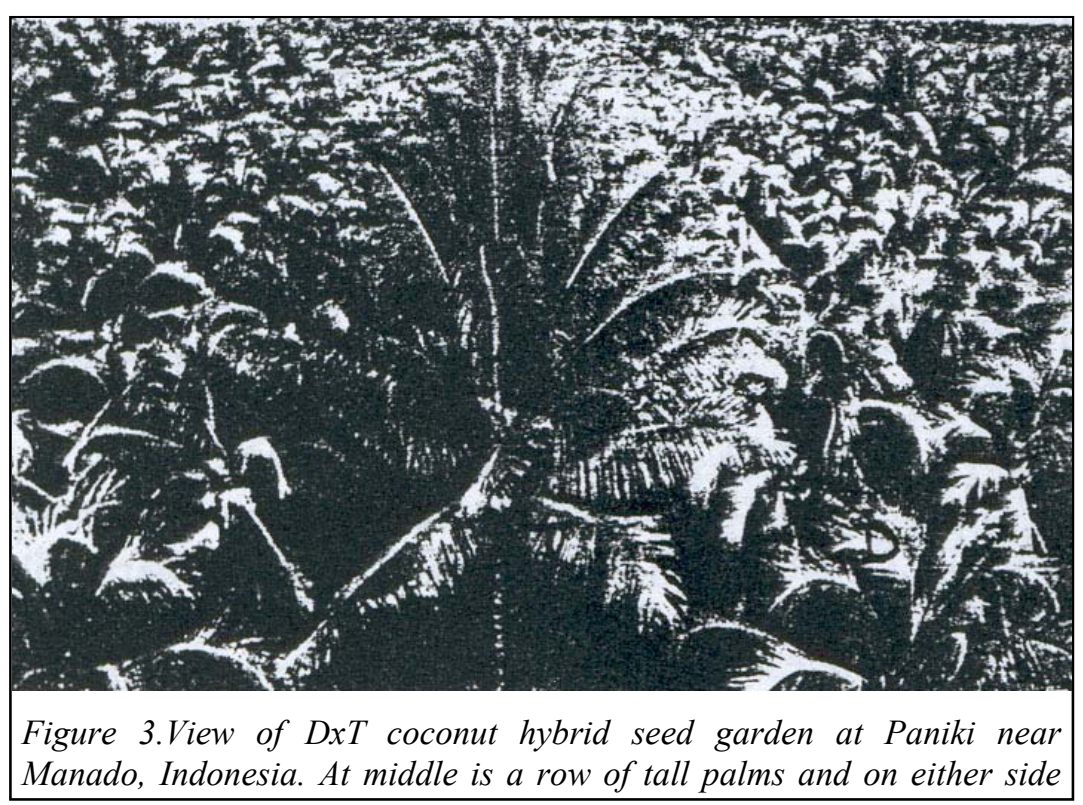

Table 2.

Analysis of Nias yellow dwarf spadix for different kinds of flowers

\begin{tabular}{|c|r|r|r|r|r|r|c|}
\hline \multirow{2}{*}{ Spikes } & \multicolumn{3}{|c|}{ No. female flrs } & \multicolumn{3}{|c|}{ No. male flrs } & \multirow{2}{*}{$\begin{array}{c}\text { Herma- } \\
\text { phrodite Flrs. }\end{array}$} \\
\cline { 2 - 7 } & Twins & Singles & \multicolumn{1}{|c|}{ Total } & Twins & Singles & \multicolumn{1}{c|}{ Total } & (15 \\
\hline 1 to 5 & - & 15 & 15 & 676 & 346 & 1,022 & 2 \\
$6-10$ & 2 & 20 & 22 & 706 & 317 & 1,023 & 3 \\
$11-15$ & 4 & 16 & 20 & 666 & 287 & 953 & 3 \\
$16-20$ & 2 & 16 & 18 & 596 & 275 & 871 & 1 \\
$21-25$ & 2 & 18 & 20 & 594 & 237 & 831 & 1 \\
$26-30$ & 2 & 22 & 24 & 538 & 232 & 770 & - \\
$31-32$ & - & 8 & 8 & 212 & 83 & 295 & - \\
Terminus & - & 4 & 4 & 60 & 40 & 100 & 10 \\
\hline Total & 12 & 119 & 131 & 4,048 & 1,817 & 5,865 & 20 \\
\hline
\end{tabular}

To understand how conunon is the production of bisexual flowers among Nias yellow dwarf palms, a random survey was conducted on 200 palms where flowers of three consecutive spadices could, be examined. The number of hermaphrodite flowers per palm in the three spadices examined ranged from zero to four. Out of the 200 palms, 54 had at least one bisexual flower. In other words, $27 \%$ of the Nias dwarf palms are polygarno-monoecious (Davis et al, 1981). If we had examined more spadices per paim, the percentage of hermaphrodite-flower producing palms might have increased. These bisexual flowers which often escape emasculation, could be potential sources of pollen that would interfere with the planned breeding prograrnme.

After concluding the survey for hermaphrodite flowers among Nias dwarf palms, another spadix from one of the Nias dwarf palms at the Paniki seed garden was found to possess numerous hermaphrodite flowers, more than the number of female flowers in it (Fig. 4). These spikes are almost exactly similar to those of the tall variety paim from India some of whose spikes are seen in Fig. 2. Production of twin female flowers thus seenis to be common to both the tall and dwarf varieties. 


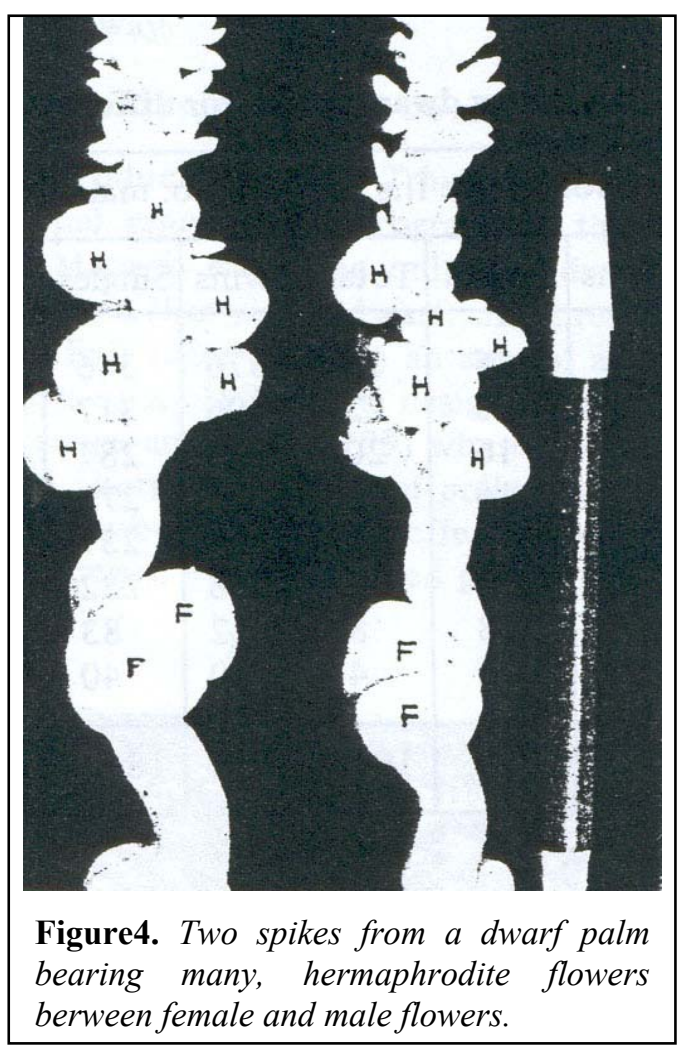

\section{Morphology of bisexual flowers}

In size and according to the position the bisexual flowers occupy the spikes, they are intermediates between normal. female and male flowers. However, there is wide variation.in the size and morphology of hermaphrodite flowers. In Fig. 5, are seen three marked female flowers (F) and eight hermaphrodite flowers $(\mathrm{H})$. The hermauhrodites can be grouped into three categories. In group one, the flowers are more like female flowers. Here each flower has two whorls of three, normal-shaped, wide perianth lobes. Its ring of starninodes has, developed only partially. One or two anthers develop partially holding within very few pollen grains. Other starninodes grow merely the filament without forming an anther. This category of bisexual flowers do not unfold their perianths as the male flowers do. Ovary is well-cleveloped and some of them grow into fruits. The second category of bisexual flowers are smaller than those of the first category. Here the perianths do not develop completely like those in female flowers. Some remain narrow, thus providing windows for the stamens to emerge at the time of the male phase of the spadix (Fig. 6). Most of the stamens grow their anther, which are of different shapes. Only some of them have functional pollen gains.

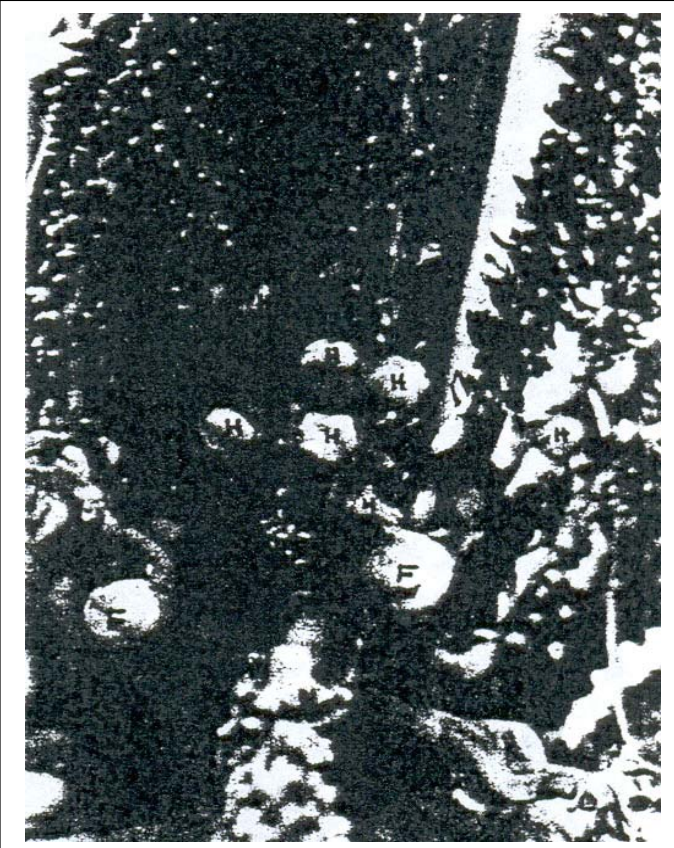

Figure 5. Portion of spadic of Nias dwarf palm bearing normal female flowers $(F)$, hermaphrodire flowers $(H)$ and numerous males. The bisexual flowers vary in size.

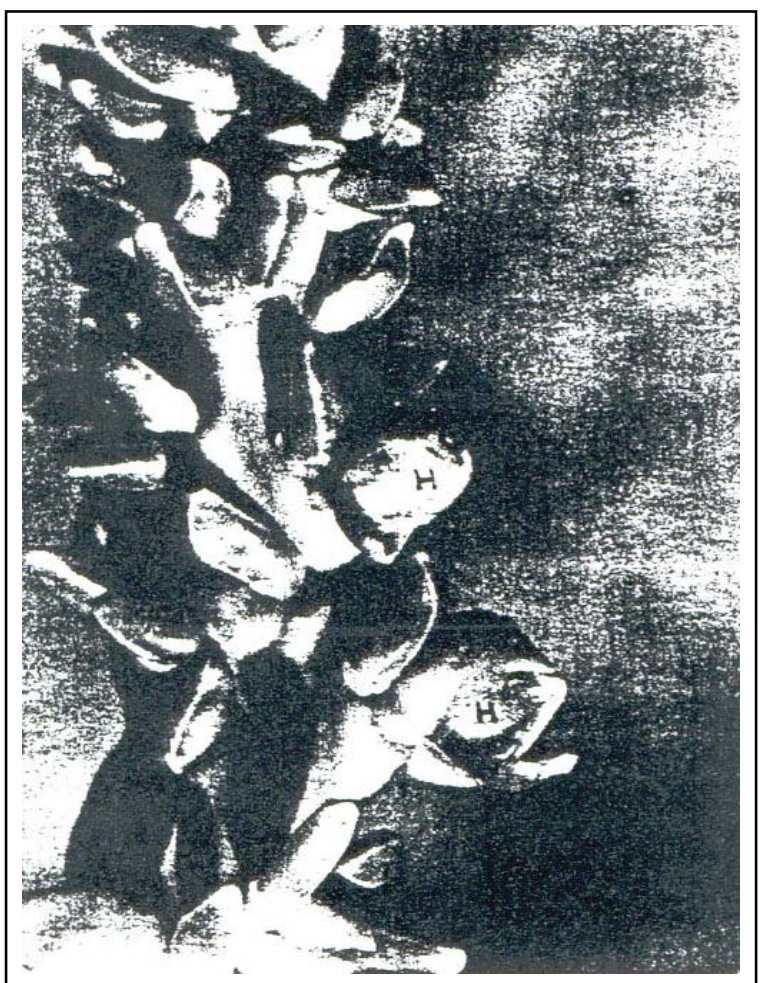

Figure 6. Portion of spike showing many male and two hermaphrodite flowers. Partially developed Stamens appear through window of hermaphrodite flowers. 
Ovary is partially developed, and they do not develop into fruit. The third category bisexual flowers resemble the male flowers although they are much larger. Their sepals are smaller than the three valvate petals. Petals unfold during anthesis when the six, developed stamens emerge. The pistils are very small and almost sterile. None of these flowers develop into fruits. Such flowers are generally harmless in a hybrid seed garden as they will get removed while emasculation.

\section{Influence of coconut hertnaphrodite flowers in breeding}

Hybridization in the coconut is effected between tall strains. between dwarf and tall varieties (or tall $\mathrm{x}$ dwarf), and to a very small extent between dwarf strains. In India, production of $\mathrm{T} x \mathrm{D}$ by assisted pollination is still very Popular where careful emascwa tion of tall mothers is important. In the different techniques employed, in spite of adopting good controi measures. some of the resultant seedlings turn out to be similar to the seed parent. The percentage of such seedlings depends on the extent of precaution taken to prevent self-pollination. the genetic make-up of the seed and pollen parents as well as on whether the seed parents produce hermaphrodite flowers or not. Information kindly supplied by coHeagues from different countries on the percentages of inbred dwarf seedlings appearing in dwarf $x$ tall crossings involving different parents are given in Table 3. Of these some are the results of controlled Pollination by the use of pollination bags and the rest are from mass pollination techniques.

Table 3.

Percentages of inbred dwarf seedfings resulting from dwarf $x$ tall crossings in different countries (based on number of nuts sown)

\begin{tabular}{|l|l|r|r|r|}
\hline \multicolumn{1}{|c|}{ Location/Source } & \multicolumn{1}{c|}{$\begin{array}{c}\text { Seed parent } \\
\text { (dwarf) }\end{array}$} & $\begin{array}{c}\text { Hybrids } \\
\text { (Nos. or \%) }\end{array}$ & $\begin{array}{c}\text { Inbreds } \\
\text { (dwarfs) }\end{array}$ & $\begin{array}{c}\text { Percentage } \\
\text { of dwarfs/inbreds }\end{array}$ \\
\hline Indonesia & & & & \\
LPTI & (a) Nias yellow & 558 & 74 & 11.71 \\
PNP X & (b) Nias yellow & 1,183 & 145 & 10.92 \\
& (a) Nias yellow & 20,303 & 2,147 & 9.56 \\
Ternate & (b) Malayan red & 2949 & 276 & 8.56 \\
Malaysia & Malayan yellow & 938 & 91 & 8.84 \\
$\quad$ & & & \\
$\quad$ Highlands Estate & Malayan yellow & $85.0 \%$ & & 15.0 \\
Jamited Plantation Berhad & Malayan red & $95.0-97.0 \%$ & & $3.0-5.0$ \\
India & Malayan yellow & $92.0 \%$ & & 8.00 \\
Ivory Coast & Chowgat orange & $84.51 \%$ & & 15.49 \\
Sri Lanka & Malayan yellow & $95.0-97.0 \%$ & & $3.0-5.0$ \\
& Not Known & $95.0-98.0 \%$ & & $2.0-5.0$ \\
\hline
\end{tabular}

Note : So far as the Phillipines are concerned, Prof. Juan Carlos of the Universiry of the Philippines at Los Banos was able to obtain $97 \%$ or $98 \%$ hybrids with yellow and red dwarfs as seed parents each occupying only 0.5 ha garden (Personal communication).

From data supphed in Table 3, one may presume that on an average, not less than eight per cent of the millions of 'hybrid seeds' produced become dwarfs which is a matter for concem since the share, of the ainount spent on supervision, labour, attention, storage and transport, etc., for these seeds is quite large. It is hoped that in their attempts to reduce the production of dwarf seeds (where dwarf seedlings are not in demand) coconut breeders will give the required attention to ehminate the hermaphrodite flowers. Palms known to produce regularly large numbers of bisexual flowers should be removed from seed gardens. 


\section{Precaution needed to minimise production of dwarf seeds in intervarietal hybridization}

In order to minimize the percentage of 'inbred' dwarfs in $\mathrm{D} x \mathrm{~T}$ hybridization, various precautions are, adopted by coconut breeders in different countries. Judging from results, the most rigorous precautions seem to have been followed in Sri Lanka and the Ivory Coast in their hybrid production prograrnme. In Ivory Coast, effecting a cross between Malayan yellow dwarf and West African tall has yielded the familiar PB 121. The procedure as reported by de Nuce and Rognon (1972) consists of systematic removal of all male flowers produced by mother palms to avoid any emission of pollen. The operation is carried out as soon as the spathe opens.

When a slit appears thrpugh which a few begins to emerge, the tip of the spathe is cut off and the remaining portion tom lengthwise which is also cut away at the base. The spikes, trimmed 5 or 6 $\mathrm{cm}$ above the topmost female flower, are collected in a bag and burnt. The remaining male flowers are detached by hand. The emasculation work is methodically organised and strictly checked. The emasculator examines the state of the inflorescences of the seed parents 5 or 6 times a day. One person is responsible for 250-300 trees resulting in 300-400 emasculations each month. Each operation is recorded and the quality of the work of the emasculator is checked by a supervisor. It is further reported that the supervisor keeps his team up to mark at all times. Because of these precautions, $95 \%$ to $97 \%$ legitimacy is reported from Ivory Coast. Most of these being expensive operations, strict vigilance may not bepossible when very large quantities of seeds have to be produced for distribution within relatively short periods.

Coconut breeders elsewhere take further precautionary steps. In Malaysia, according to Hoak (1980), all inflorescences are emasculated before the spathe has a chance to open by itself. A $2.0 \%$ formalin is sprayed on a limited scale to kill the pollen from flowers that accidentally slip pass the flower catcher. Abnormal inflorescences that fail to elongate are chiselled off. A reserve gang of emasculators is maintained for emergency and for service during peak crop season.

Inspite of ail these, unexpected contingencies may arise that would affect the efficient arrangements and reduce the hybrid recovery. According to de Nuce (1980), due to a drastic reduction in the quantity of pollen used at the seed garden at Lampung (Indonesia), the percentage of dwarfs could go upto $10.0 \%$ even though under normal conditions, dwarfs appeared only less than $2.0 \%$. This is a sound prediction since the results we observed from over 20,000 seedlings reached $9.56 \%$ (Table 3). Another instance of unexpected results was reported by de Nuce. In Ivory Coast, where normally only less than $5.0 \%$ dwarfs appear in dwarf $x$ tall crosses, such a percentage increased to $15 \%$ because part of their garden was slightly contarninated by pollen from hybrid palms in spite of a $300 \mathrm{~m}$-wide barrier. Hermaphrodite flower is another source of contarnination which has to be culled at the time of emasculation. 


\section{REFERENCES}

Davis, T. A., Anandan, A. P., and K. P. V. Menon (1954). Hermaphroditism in Cocos nucifera L. Indian Coconut J. 7: 133142.

Davis, T. A., Sudasrip, H., and H. Azis (1981). Significance of hermaphrodite flowers in coconut breeding. Proc. Indian Natn. Sci. Acad. B4 7: 527-535.

Davis, T. A., Sudasrip, H., and S. N. Darwis (1985). Coconut Research Institute, Manado, Bogor.

De Nuce Lamothe, M., (1 980). Personal communication.

De Nuce Lamothe, M., and F. Rognon (1972). The production of hybzid coconut seed by controlled natural pollination. Olleagineux, 27: 483-488.

Hoak, O. L. (1 980). Personal communication.

Jacob, K. C. (1941). A new variety of coconut palm (Cocos nucifera L. var. spicata, K. C. Jacob). J. Bombay Nar. Hist. Soc., 41: 906-907.

Juliano, J. B., and E. Quisumbing (1931). Morphology of male flower of Cocos nucifera L. Phillipine J. Sci., 45: 449-458.

Liyanage, D. V., and Hasman Azis (1983). A new technique for establishing coconut seed gardens. Cocos, 1: 1-6.

Patch, T. (1913). The flower of the Coconut. Trop. Agriculturist, 41: 449-455.

Patel, J. S., (1938). The coconut, a monograph. Madras.

Rao, G. T., (1948). A note on the occurrence of a hermaphrodite flower in coconut (Cocos nucifera L.). J. Indian Bot. Soc., 27: 205-211. 